positive linear relationship between adherence and cessation rates however, adherence to NRT among unmotivated smokers is uncertain.

Methods Chinese smokers who aged $\geq 18$, had no intention to quit within 4-week and had no contraindication to NRT were recruited and randomly allocated to Group A1, A2 and B in a RCT. Only Group A1 and A2 were provided 8-week free NRT. We reported 8-week adherence rate to NRT at 3-month and reasons for noncompliance among subjects in Group A1 and A2.

Results From October 2004 to April 2007, 1154 smokers were recruited (Group $\mathrm{A} 1=479 ; \mathrm{A} 2=449 ; \mathrm{B}=226$ ). Subjects in Group A1 and $A 2(n=928)$ were $42.0 \pm 10.3$ year-old and smoked $19.6 \pm 9.4$ cigarettes daily on average. We contacted 797 subjects (85.9\%) for 3month follow-up, but those who did not receive 8-week free NRT $(\mathrm{n}=115 ; 14.4 \%)$ were removed from the analysis. $55.4 \%(378 / 682)$ used NRT as the recommended regime, $41.6 \%$ (284/682) did not fully comply with the prescription and $3.0 \%(20 / 682)$ even did not use it. Among $304(n=284+20)$ who did not comply, "Forget to use" $(24.0 \%)$ and "Side effects" (14.5\%) are the two most cited reasons for non-compliance.

Conclusion The adherence rate in this study is more encouraging compared to a local study (20\%) which only provided 1-week free NRT. Thus, providing the entire course of free NRT seems to yield an improved NRT adherence among unmotivated Chinese smokers.

\section{SP4-23 SOCIAL POSITION AND RISK OF DEMENTIA IN PEOPLE WITH HIGH LEVELS OF ABSOLUTE POVERTY BUT LOW LEVELS OF CARDIOVASCULAR RISK FACTORS AND DEPRESSION: THE ANHUI COHORT STUDY}

doi:10.1136/jech.2011.142976p.17

${ }^{1} \mathrm{R}$ Chen.* ${ }^{1}$ University of Wolverhampton, Wolverhampton, UK; ${ }^{2}$ Anhui Medical University, Hefei, China

Introduction The relationship between dementia and socioeconomic deprivation is unclear. This study examined the association between social position and dementia, and determined the prevalence of dementia diagnosed using the 10/66 algorithms in people with high levels of absolute poverty but low levels of cardiovascular risk factors and depression.

Methods Prospective cohort study of 1766 elders in rural and urban community-dwellings in Anhui, China. Standardised mental status measures were administered and socioeconomic and risk factors were characterised at baseline. At 6.2-year follow-up, dementia cases were identified using the 10/66 algorithms, causes of death and reports by psychiatrists.

Results The world age-standardised prevalence of dementia diagnosed by the $10 / 66$ algorithms was $5.41 \%$ (95\% CI $(4.26 \%$ to $6.55 \%)$ ); in men $4.38 \%(2.88 \%$ to $5.89 \%)$ and in women $6.44 \%$ $(4.76 \%$ to $8.13 \%)$. The risk of dementia significantly and independently increased with age, lower educational level, uncontrolled hypertension, not watching television, feeling lonely and hearing problems. Compared to those that achieved an educational level of $\geq$ secondary school and middle income participants, those with lower educational attainment and in the lowest or highest income groups had a higher risk of dementia; multiple adjusted OR (AOR) were 2.99 (1.24 to 7.23) and 3.30 (1.09 to 9.97) respectively. Business/non-labouring participants with educational levels of $\leq$ primary school had the highest risk of dementia (AOR 3.80 (1.43 to 10.1)) compared to other combinations of occupational class and educational level.

Conclusions Increasing income and minimising the gap in income between poor and rich may reduce the epidemic of dementia in China. Increasing levels of education and TV watching could be an efficient measures to prevent dementia in developing countries.
SP4-24 SELF-REPORTED TOBACCO SMOKING PRACTICES AMONG MEDICAL STUDENTS AND THEIR PERCEPTIONS TOWARDS TRAINING ABOUT TOBACCO SMOKING IN MEDICAL CURRICULA: A CROSS-SECTIONAL, OUESTIONNAIRE SURVEY IN MALAYSIA, INDIA, PAKISTAN, NEPAL, AND BANGLADESH

doi:10.1136/jech.2011.142976p.18

${ }^{1} \mathrm{C}$ Sreeramareddy, ${ }^{*}$ 'S Suri, ${ }^{2} \mathrm{R}$ G Menezes, ${ }^{2} \mathrm{H} \mathrm{N}$ Harsha Kumar, ${ }^{3} \mathrm{M}$ Rehman, ${ }^{3} \mathrm{R}$ Islam, ${ }^{4} \mathrm{M}$ Shah, ${ }^{5} \mathrm{~B}$ Sathian, ${ }^{1} \mathrm{X}$ V Pereira, ${ }^{6} \mathrm{U}$ Shetty, ${ }^{7} \mathrm{~V}$ R Vaswani. ${ }^{1}$ Melaka Manipal Medical College, Melaka, Malaysia; ${ }^{2}$ Kasturba Medical College, Mangalore, India; ${ }^{3}$ Faridpur Medical College, Faridpur, Bangladesh; ${ }^{4} \mathrm{CMH}$, Lahore Medical College, Lahore, Pakistan; ${ }^{5}$ Manipal College of Medical Sciences, Pokhara, Nepal; ${ }^{6}$ AJ Institute of Medical Sciences, Mangalore, India; ${ }^{7}$ Yenepoya Medical College, Mangalore, India

Introduction Tobacco smoking issues in developing countries are usually taught non-systematically as and when the topic arose.

Methods A cross-sectional questionnaire survey was carried out among final year undergraduate medical students. An anonymous, self-administered questionnaire included items on demographic information, students' current practices about patients' tobacco smoking habits, their perception towards tobacco education in medical schools on a five point Likert scale. Questions about tobacco smoking habits were adapted from GHPSS questionnaire

Results Overall response rate was $81.6 \%$ (922/1130). Median age was 22 years while $50.7 \%$ were males and $48.2 \%$ were females. The overall prevalence of "ever smokers" and "current smokers" was $31.7 \%$ and $13.1 \%$ respectively. A majority (>80\%) of students asked about patients' smoking habits. Only a third of them did counselling, and assessed the patients' willingness to quit. Majority of the students agreed about doctors' role in tobacco control as being role models, competence in smoking cessation methods, counselling, and the need for training about tobacco cessation in medical schools. About $50 \%$ agreed that current curriculum teaches about tobacco smoking but not systematically and should be included as a separate module. Majority of the students indicated that topics about health effects, nicotine addiction and its treatment, counselling, prevention of relapse were important or very important in training about tobacco smoking.

Conclusion Medical educators should consider revising medical curricula to improve training about tobacco smoking cessation in medical schools. Our results should be supported by surveys from other medical schools in developing countries of Asia.

\section{SP4-25 POPULATION SURVEY OF SEMEN QUALITY IN YOUNG SCOTTISH MEN}

doi:10.1136/jech.2011.142976p.19

${ }^{1} \mathrm{P}$ Warner, ${ }^{*}{ }^{2} \mathrm{~S}$ Irvine, ${ }^{3} \mathrm{R}$ Sharpe, ${ }^{4} \mathrm{R}$ Agius, ${ }^{5} \mathrm{~A}$ Porter, ${ }^{6} \mathrm{~T}$ Farragher. ${ }^{1}$ Centre for Population Health Sciences, The University of Edinburgh, Edinburgh, UK; ${ }^{2} \mathrm{NHS}$ Education for Scotland, Glasgow, UK; ${ }^{3}$ MRC Human Reproductive Sciences Unit, Edinburgh, UK; ${ }^{4}$ Centre for Occupational and Environmental Health, University of Manchester, Manchester, UK; ${ }^{5}$ Public Health Directorate, NHS Hull, Hull, UK; ${ }^{6}$ Institute of Health Sciences, University of Leeds, Leeds, UK; ${ }^{7}$ NHS National Services Scotland, Edinburgh, UK

Introduction For years concerns have been raised that male semen quality is declining globally, and that this is a birth cohort effect. However, there has been a degree of subject selection bias and trend estimates have been ecological. Our study aimed to examine semen quality in a representative sample of a general population (Scottish), and to explore trend by birth year within the data.

Methods A randomly selected sample of 22-32 year-old Scottishborn men were recruited to a survey of male reproductive health Background information was collected by questionnaire and men were asked to provide a semen sample for analysis. 
Results Semen assessments were obtained for 502 men. This group was representative of the general population regarding social class, education and geography. The median sperm concentration of samples was $48 \times 10^{6} / \mathrm{ml}$, but after adjustment to a mean abstinence of 4 days, $64 \times 10^{6} / \mathrm{ml}$. In these adjusted data, "low" sperm counts (below $20 \times 10^{6} / \mathrm{ml}$ ) were found in $18 \%$ of men ( $95 \%$ CI $15 \%$ to $21 \%$ ). However, the prevalence of "low" sperm counts showed no trend across the 10-year range of birth years.

Conclusion This first report of sperm concentration in a random sample of a general population shows that nearly a fifth of men had poor semen quality. Further work is required to clarify the fertility relevance of a single low sperm concentration when there is no imposition of abstinence prior to sample, and to understand cause of the fertility deficit found in many survey participants.

\section{SP4-26 BURDEN OF TOXIC METAL EXPOSURE AMONG SCHOOL- AGED CHILDREN IN UNITED ARAB EMIRATES}

doi:10.1136/jech.2011.142976p.20

${ }^{1} \mathrm{~S}$ Yousef, ${ }^{*}{ }^{1} \mathrm{~A}$ Adem, ${ }^{2} \mathrm{~V}$ Eapen, ${ }^{1} \mathrm{~T}$ Zoubeidi, ${ }^{1} \mathrm{M}$ Kosanovic, ${ }^{1} \mathrm{~A}$ A Mabrouk. ${ }^{1} \mathrm{U} A E$ University, Al Ain, Abu Dhabi, United Arab Emirates; ${ }^{2}$ University of New South Wales, New South Wales, Australia

Background Environmental toxic metal exposure may adversely affect children's development and behaviour. Data are lacking about heavy metal exposure in children in UAE and Gulf countries.

Objectives To determine blood concentrations of 12 heavy metals in school-age children in Al Ain City, UAE.

Methods It was a cross sectional study. One hundred and forty seven subjects were selected from nine elementary schools. The mean age was 8.4 years ( $S D \pm 2$ years). ICP-MS instrument was used to determine the metal concentration. Data analysis was performed using the SPSS.

Results The (mean \pm SD) blood level for study children $(n=146)$ of lead was $25.86 \pm 13.06 \mathrm{ppb}$, cadmium $0.31 \pm 0.25 \mathrm{ppb}$, arsenic $10.74 \pm 4.71 \mathrm{ppb}$, mercury $1.39 \pm 1.16 \mathrm{ppb}$, manganese $1.85 \pm 1.09$ ppb, nickel 9.18 $\pm 8.23 \mathrm{ppb}$, zinc $3731 \pm 1752 \mathrm{ppb}$, chromium $2.10 \pm 1.53 \mathrm{ppb}$, cobalt $0.65 \pm 0.40 \mathrm{ppb}$, copper $1064 \pm 403 \mathrm{ppb}$, molybdenum $1.59 \pm 1.25 \mathrm{ppb}$, and antinomy $0.60 \pm 0.63 \mathrm{ppb}$.

Conclusions Reference values for the trace metals vary markedly; especially due to sampling, age, diet, exposure differences and analytical techniques used. In this study, the mean blood lead was below the CDC's recommended level of concern $(>10 \mu \mathrm{g} / \mathrm{dl})$ and with cadmium, mercury and chromium were comparable with similar studies elsewhere; manganese and zinc were slightly lower; copper and molybdenum were slightly higher while arsenic and cobalt much higher. Blood screening and surveillance linked to appropriate public health interventions is strongly recommended for UAE.

\section{SP4-27 HIGH PREVALENCE OF ESCHERICHIA COLI AND HUMAN ADENOVIRUS IN WATER, MUSSELS AND YOUNG CHILDREN WITH ACUTE GASTROENTERITIS LIVING IN MANGROVE REGION}

doi:10.1136/jech.2011.142976p.21

R Keller, ${ }^{*}$ J Justino, S T Cassini, E Maciel. Federal University of Espirito Santo, Vitória, Espirito Santo, Brazil

Introduction Several studies have shown that many aquatic ecosystems are often contaminated with pathogenic microorganisms through the discharge of untreated or partially treated sewage. The maintenance of water quality is a major challenge for governments with direct consequences on the health of the environment and the population. Mangrove is an important source of livelihood for fishermen living in the region of Vitória, ES, Brazil. In the last years high numbers of gastroenteritis cases have been reported in this region suggesting an association between the consumption or handling of contaminated water and mussels and the development of gastrointestinal diseases. The aim of this study was to investigate the sanitary quality of water and mussels and to evaluate an association of gastroenteritis cases and the presence of adenovirus and bacterial indicators of fecal pollution in these samples.

Methods Feces of children from 0 months to 12 years living in the areas of study and diagnosed with gastroenteritis are collected and evaluated for the presence of adenovirus. Water and mussels are sampled monthly and analysed for adenovirus by PCR and nestedPCR; total coliforms and $E$ coli were detected using the Total Coliform/E coli Enzyme substrate test (Colilert $($ )).

Results All water samples and mussels analysed were positive for $E$ coli. Adenovirus genome was detected in $76 \%$ of water samples and $100 \%$ of mussel samples collected.

Conclusion These data shows that this area is highly contaminated with domestic sewage and indicates that consumption of seafood may be associated with cases of gastroenteritis reported in the region.

\section{SP4-28 CHILDBEARING DURING ADOLESCENCE AND OFFSPRING MORTALITY: COMPARISON OF THREE POPULATION BASED COHORTS IN SOUTHERN BRAZIL}

doi:10.1136/jech.2011.142976p.22

${ }^{1}$ M C Restrepo, ${ }^{*}$ A M B Menezes, ${ }^{1}$ I da Silva Santos, ${ }^{1}$ B L Horta, ${ }^{2}$ F C Barros, ${ }^{1} \mathrm{C}$ G Victora. 'Universidade Federal de Pelotas, Pelotas, Rio Grande do Sul, Brazil, ${ }^{2}$ Universidade Católica de Pelotas, Pelotas, Rio Grande do Sul, Brazil

Objective To assess the association between childbearing age and risk of offspring mortality in three birth cohort studies.

Setting Pelotas, Southern Brazil

Methods All hospital births which occurred in 1982 ( $n=6011), 1993$ $(n=5304)$ and $2004(n=4287)$ were identified and these infants were followed-up. Deaths were monitored through vital registration, visits to hospitals and cemeteries. The analyses were restricted to women younger than 30 years who delivered singletons $(72 \%, 70 \%$ and $67 \%$ of the original cohorts, respectively). Maternal age was categorised into three groups $(<16,16-19$, and 20-29 years). Additional analyses compared mothers aged $12-19$ and $20-29$ years. The outcome variables included fetal, perinatal, neonatal, post-neonatal and infant mortality. Potential confounders were family income, maternal education, maternal colour/race, marital status, parity, and pre-pregnancy body mass index. Crude and adjusted ORs were estimated with logistic regression models.

Results There were no interactions between maternal age and cohort year. After adjustment for confounding, the pooled ORs for infant death were 1.08 (95\% CI 0.42 to 2.78) for mothers younger than 16 years, 1.48 (1.03 to 2.12) for 16-19-year-olds, and 1.45 (1.01 to 2.07) for those aged 12-19, compared to a 20-29-year-old mothers. The excess risk was due to post-neonatal deaths.

Conclusion The slightly increased risk of post-neonatal mortality among the offspring of adolescent mothers suggests that social and environmental factors may be more important than maternal biologic immaturity. The possibility of residual confounding cannot be ruled out. 